\title{
Angio-oedema associated with colistin
}

A A Abulfathi, ${ }^{1}$ MBBS; T Greyling, ${ }^{2}$ MB ChB, FCP (SA), Cert ID (SA) Phys; M Makiwane, ${ }^{1}$ MB ChB, Dip HIV Man (SA), PG Dip (Pharm Med); M Esser, ${ }^{3} \mathrm{MB}$ ChB, MMed (Paed), Cert Rheum; E Decloedt, ${ }^{1}$ MB ChB, BSc Hons (Pharm), FCCP (SA), MMed (Clin Pharm)

${ }^{1}$ Division of Clinical Pharmacology, Faculty of Medicine and Health Sciences, Stellenbosch University, Tygerberg, Cape Town, South Africa

${ }^{2}$ Division of Infectious Diseases, Faculty of Medicine and Health Sciences, Stellenbosch University, Tygerberg, Cape Town, South Africa

${ }^{3}$ Immunology Unit, Medical Microbiology, National Health Laboratory Service Tygerberg; and Department of Pathology, Stellenbosch University, Tygerberg, Cape Town, South Africa

Corresponding author: A A Abulfathi (aaabulfathi@sun.ac.za)

A 50-year-old woman known to have type 1 diabetes mellitus presented with a rare case of angio-oedema associated with colistin use. The angio-oedema was temporally associated with the use and discontinuation of colistin with the reasonable exclusion of important differential diagnoses. Pseudoallergy may be a probable underlying mechanism. However, we cannot exclude the possibility of hereditary angio-oedema type 2 or 3 , or that her concomitant medications (particularly enalapril) and her renal impairment contributed to the risk and severity of her angio-oedema.

S Afr Med J 2016;106(10):990-991. DOI:10.7196/SAMJ.2016.v106i10.10835

We present what is to our knowledge a rare presentation of colistin-induced angiooedema. $^{[1]}$

\section{Case report}

A 50-year-old woman presented to Tygerberg Hospital, Cape Town, South Africa (SA), with dysuria, and suprapubic and lower abdominal pain. She was known to have had type 1 diabetes mellitus for 24 years and had microvascular complications in the form of retinopathy (with blindness of the right eye), neuropathy and nephropathy. Her estimated glomerular filtration rate had declined from a baseline of $31 \mathrm{~mL} / \mathrm{min} / 1.73 \mathrm{~m}^{2} 2$ months earlier to $18 \mathrm{~mL} / \mathrm{min} / 1.73 \mathrm{~m}^{2}$ at presentation. She was admitted with sepsis due to a complicated urinary tract infection and her urine cultured Acinetobacter baumannii, sensitive only to colistin. She was initiated on intravenous colistin, dose adjusted for her degree of renal impairment. Five hours after the infusion, she developed urticaria and angio-oedema involving the face, lips and tongue, but with no laryngeal involvement or anaphylaxis. She had no personal or family history of angio-oedema or of any other allergy or atopy. She was not known to have had prior exposure to colistin. At the time of angio-oedema diagnosis, she had received subcutaneous insulin (24 years), enalapril (5 years), amlodipine (5 years), simvastatin (5 years), aspirin (5 years), furosemide (1 year) and colistin (5 hours) (Fig. 1).

The patient was successfully managed with prompt discontinuation of the colistin infusion, administration of promethazine, hydrocortisone, oxygen via facemask and

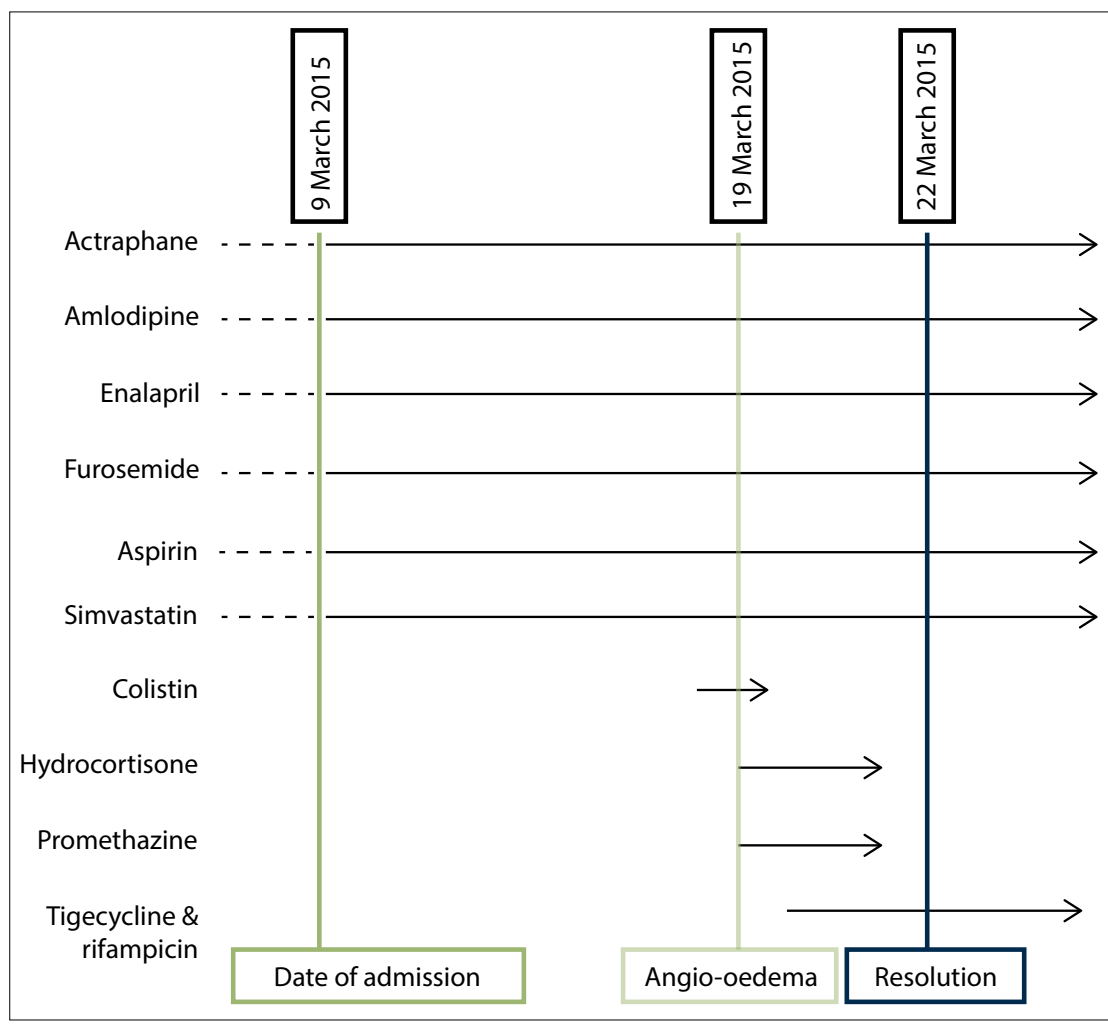

Fig. 1. Causality assessment.

supportive care, with provision for escalation of care if symptoms worsened. There was no indication for intubation, and the angio-oedema resolved over 72 hours. Her A. baumannii urosepsis was successfully treated with intravenous tigecycline and oral rifampicin.

Angiotensin-converting enzyme inhibitor (ACE-I) angio-oedema was considered, ${ }^{[2-5]}$ as
ACE-I angio-oedema may develop months or even years after commencing therapy. ${ }^{[2,4,6]}$ However, she improved and had complete resolution of symptoms despite continuing with enalapril. While other concomitant medications (insulin, amlodipine, furosemide, simvastatin) could theoretically cause angio-oedema, it is highly unlikely because of their continued use. 
Hereditary angio-oedema (HAE) type 1 or 2 is unlikely because of the absence of a family history and the first occurrence in the patient's 6th decade. ${ }^{[4,7]}$ HAE-1 was excluded with a normal C4 level of $0.23 \mathrm{~g} / \mathrm{L}$ (normal range $0.20-1.00$ ) and a slightly elevated $\mathrm{C} 1$ esterase inhibitor $(\mathrm{C} 1-\mathrm{INH})$ level of $0.49 \mathrm{~g} / \mathrm{L}(0.21-0.40)$. The normal C4 level makes HAE-2 unlikely, but a definite diagnosis requires evaluation of the function of $\mathrm{C} 1-\mathrm{INH}$, which is not readily available in SA. The elevated C1-INH level observed in our patient may have been due to the underlying sepsis. HAE-3, which is more common in females and at an older age, remains a possibility, but F-12 gene mutation testing is unavailable in SA.

Acquired angio-oedema, also known as acquired C1-INH deficiency, is due to autoantibodies against $\mathrm{C} 1-\mathrm{INH}$ as a result of autoimmune or lymphoproliferative diseases. ${ }^{[3,8]}$ This was considered because our patient had type 1 diabetes mellitus and was therefore at risk of other autoimmune diseases. However, she had a normal C3 level of $1.05 \mathrm{~g} / \mathrm{L}(0.50-1.53)$.

The temporal association between the administration of colistin and development of symptoms that resolved with the prompt discontinuation of colistin makes the diagnosis of colistin-induced angio-oedema likely. Rechallenge with colistin would have confirmed our diagnosis but was considered inappropriate. Pseudoallergy may be the most likely mechanism for our patient's colistin-induced angio-oedema. This is a result of the offending agent binding directly to mast cells and inducing their degranulation with release of inflammatory mediators, particularly histamine, ${ }^{[3]}$ leading to angio-oedema and urticaria. ${ }^{[9]}$ It does not require IgE mediation ${ }^{[3,10]}$ and no prior sensitisation is needed.

\section{Conclusion}

We present what is to our knowledge a rare case of colistininduced angio-oedema temporally associated with the use and discontinuation of colistin with the reasonable exclusion of important differential diagnoses. However, we cannot exclude the possibility that her concomitant medication (particularly enalapril) and her renal impairment contributed to the risk and severity of her angiooedema.

1. Medicines \& Healthcare Products Regulatory Agency. Public Assessment Report: Decentralised procedure: Colistimethate sodium. http://www.mhra.gov.uk/home/groups/par/documents/ websiteresources/con152847.pdf (accessed 25 August 2016)

2. Lipski SM, Casimir G, Vanlommel M, Jeanmaire M, Dolhen P. Angiotensin-converting enzyme inhibitors-induced angioedema treated by $\mathrm{Cl}$ esterase inhibitor concentrate (Berinert ${ }^{*}$ ): About one case and review of the therapeutic arsenal. Clin Case Rep 2015;3(2):126-130. DOI:10.1002/ccr3.171

3. Jaiganesh $\mathrm{T}$, Wiese $\mathrm{M}$, Hollingsworth J, et al. Acute angioedema: Recognition and management in the emergency department. Eur J Emerg Med 2013;20(1):10-17. DOI:10.1097/MEJ.0b013e328356f76e the emergencenting angioedema and hereditary angioedema: A comparison study of attack severity. Intern Med
and

5. Decloedt E, Freercks R, Maartens G. Cerebral angioedema associated with enalapril. Br J Clin Pharmacol 2009;68(2):271-273. DOI:10.1111/j.1365-2125.2009.03452.x

6. Orr KK, Myers JR. Intermittent visceral edema induced by long-term enalapril administration. Ann Pharmacother 2004;38(5):825-827. DOI:10.1345/aph.1D458

7. Moran E, Isaacs GS, Naidoo B, Pudifin DJ. Hereditary C1 esterase deficiency in a Zulu kindred. S Afr Med J 2009;99(1):40-42.

8. Triggianese P, Chimenti MS, Toubi E, et al. The autoimmune side of hereditary angioedema: Insights on the pathogenesis. Autoimmun Rev 2015;12(8):4-8. DOI:10.1016/j.autrev.2015.03.006

9. Grigoriadou S, Longhurst HJ. Clinical Immunology Review Series: An approach to the patient with angio-oedema. Clin Exp Immunol 2009;155(3):367-377. DOI:10.1111/j.1365-2249.2008.03845.x10

10. Lewis LM. Angioedema: Etiology, pathophysiology, current and emerging therapies. J Emerg Med 2013;45(5):789-796. DOI:10.1016/j.jemermed.2013.03.045

Accepted 29 March 2016 